\section{Oral anticoagulant therapy for older patients with atrial fibrillation}

\author{
Mario Bo, Enrico Brunetti \\ Section of Geriatrics and Bone \\ Metabolic Diseases, Department of \\ Medical Sciences, University of Turin, \\ Italy
}

\begin{abstract}
Atrial fibrillation (AF) is one of the most common cardiac arrhythmias. Its incidence and prevalence increase with age, representing a significant burden for health services in western countries. The most feared consequence of $\mathrm{AF}$ is cardio-embolic stroke, accounting for roughly one third of ischemic strokes in the elderly. Oral anticoagulant therapy is currently recommended for patients with $\mathrm{AF}$ and a $\mathrm{CHA}_{2} \mathrm{DS}_{2}$-VASc score $\geq 2$ in men and $\geq 3$ in women, but it is widely underused, particularly in the oldest patients who, in reason of their higher risk of stroke, might benefit more from it. Among the main reasons for anticoagulant underuse in older patients, advanced age itself, physician's perceived high risk of age-related and fall-related bleedings, and difficulties in monitoring vitamin $\mathrm{K}$ antagonists-based therapies are the most frequently reported.
\end{abstract}

\section{General considerations on oral anticoagulant therapy under-prescription in older patients}

Atrial fibrillation (AF) is one of the most common cardiac arrhythmias. Its incidence and prevalence increase with age, representing a significant burden for health services in western countries. ${ }^{1,2}$ Oral anticoagulant therapy (OAT) is currently recommended for patients with $\mathrm{AF}$ and a $\mathrm{CHA}_{2} \mathrm{DS}_{2}$-VASc score $\geq 2$ in men and $\geq 3$ in women, ${ }^{3}$ but it is widely underused, particularly in the oldest patients ${ }^{4-7}$ who, in reason of their higher risk of stroke, might benefit more from it. Studies consistently demonstrate that less than half of octogenarians are currently treated with OAT. ${ }^{1,4,6,7}$ Although temporary or permanent contraindications may partially account for this under-prescription, ${ }^{6,7}$ advanced age and short life-expectancy, fear of bleeding, perceived harm greater than benefit, poor health and geriatric syndromes appear to be the most common reasons why physicians with- hold anticoagulants. ${ }^{4-7,8}$ Noteworthy, geriatric syndromes such as frailty and functional dependence were not considered in most trials in AF patients both on vitamin $\mathrm{K}$ antagonists (VKAs) and direct oral anticoagulants (DOACs). In the absence of robust evidence driving the best use of anticoagulation in frail and complex older patients, a multidimensional algorithm covering both a standard ischemic and bleeding risk assessment and an additional anticoagulation-focused frailty assessment has been recently suggested to achieve a tailored approach in older AF patients. ${ }^{9}$ Unfortunately by now there are not validated and widely acknowledged methods to identify those older patients who, in reason of their poor general health and/or functional status, are expected not to derive a net clinical benefit from anticoagulation, and should therefore not be prescribed OAT.

It seems plausible that this persisting therapeutic reluctance relies on intimate skepticism that the clinical benefits demonstrated in randomized trials and observational studies may not be observed at the same extent in more vulnerable older patients. Specifically, safety rather than efficacy concerns appear to be the major responsible for uncertainties in OAT prescription in older patients.

\section{Vitamin $\mathrm{K}$ antagonists}

Although VKAs have been extensively studied and are familiar to the majority of clinicians, they have several well-known disadvantages. Major bleedings, including intracranial hemorrhages, represent an important complication of VKAs-based therapy, at some extent irrespective of anticoagulation quality. VKAs have well-known interactions with many foods and drugs, potentially contributing to adverse drug reactions. These are particularly frequent in older patients; in U.S. adults $\geq 65$ years warfarin is responsible of a third of all adverse drug events requiring hospital admission. There is strong evidence that the net clinical benefit of therapy with VKAs is strictly dependent on ensuring an adequate TTR, ${ }^{1,3}$ which may be particularly challenging in older patients. Indeed, some observational real-life studies, including a high proportion of patients over 75 years, have shown a poor mean quality of anticoagulation, with only about half of the time in therapeutic range. Moreover, international normalized ratio (INR) variability is maximal during the first weeks of treatment, thus potentially contributing to the highest incidence of bleeding in the first three months. Eventually, the need for frequent coagulation tests is inconvenient, particularly
Correspondence: Mario Bo, Section of Geriatrics and Bone Metabolic Diseases, Department of Medical Sciences, University of Turin, Italy.

E-mail: mario.bo@unito.it

Key words: Oral anticoagulant therapy; atrial fibrillation.

Conference presentation: paper presented at $31^{\circ}$ Congresso Nazionale SIGOT - Genova, June 8-9, 2017

Received for publication: 1 September 2017. Accepted for publication: 14 September 2017.

This work is licensed under a Creative Commons Attribution-NonCommercial 4.0 International License (CC BY-NC 4.0).

(C) Copyright M. Bo and E. Brunetti, 2017

Licensee PAGEPress, Italy

Geriatric Care 2017; 3:7038

doi: $10.4081 / g c .2017 .7038$

for frail and functionally dependent patients, thereby discouraging some of them from accepting VKAs. As a consequence, adherence to therapy is poor, and use of warfarin rapidly declines over time in many patients. Altogether these factors may have contributed to the extensive under-use of VKAsbased OAT, particularly in the elderly.

\section{Direct oral anticoagulants}

In the last years four DOACs have been approved for the prevention of thromboembolism in patients with non-valvular $\mathrm{AF}^{3}$ a direct thrombin inhibitor (dabigatran etexilate), and three factor Xa inhibitors (apixaban, rivaroxaban, and edoxaban). Although the single molecules have shown variable efficacy and safety compared to warfarin, as a class they have an equal or greater efficacy, with a strikingly reduced risk of intracranial hemorrhage. Since one of the greatest advantages of DOACs is the lack of need for routine coagulation monitoring, they are likely to widen the treatment options for frail elderly individuals.

In Table $1{ }^{10}$ we report the main efficacy and safety end-points on older patients derived from age group sub-analyses of the aforementioned phase III RCTs. Real-life studies confirm that in older patients DOACs are at least as effective as VKAs in preventing ischemic stroke and thromboembolism, and are associated with a consistent reduction in the risk of intracranial bleeding. However, safety data on major extracranial bleedings appear to be highly 
heterogeneous between different DOACs in these studies, with current evidence suggesting an apparent better safety profile for apixaban and low dose dabigatran.

\section{Conclusions}

Prescription of anticoagulants in older patients is often a troublesome decision, probably involving a global evaluation of health, residual life expectancy, functional and cognitive status, rather than a simple addition of variables within cardio-embolic and bleeding risk scales. It is likely that OAT may sometimes be perceived by physicians as futile or potentially harmful in patients with short life expectancy.

Selection of the right anticoagulant drug for stroke prevention in the elderly should be based on a global evaluation of patient's characteristics, including age, comorbidity, kidney function, overall and gastrointestinal bleeding risk, ischemic or hemorrhagic stroke history, patient's preference for low pill burden and, obviously, costs (Figure 1). ${ }^{11}$ In our view, a comprehensive geriatric evaluation should be routinely included as a part of the clinical evaluation of older patients with $\mathrm{AF}$, and a high level of surveillance should be maintained on those receiving OAT, in order to make available in the next future valuable information on the net clinical benefit of these drugs in complex real-world older patients.

Table 1. Efficacy and safety outcomes in patients $\geq 75$ years from sub-analysis of Phase III DOACs RCTs.

\begin{tabular}{|c|c|c|c|c|c|c|c|}
\hline & \multicolumn{2}{|c|}{$\begin{array}{c}\text { RE-LY } \\
\text { Eikelboom, } \\
\text { Circ } 2011\end{array}$} & $\begin{array}{l}\text { ROCKET-AF } \\
\text { Halperin } \\
\text { Circ } 2014\end{array}$ & $\begin{array}{l}\text { ARISTOTLE } \\
\text { Halvorsen Eur } \\
\text { H J } 2014\end{array}$ & $\begin{array}{l}\text { AVERROES } \\
\text { Ng Age } \\
\text { Ageing } 2016\end{array}$ & \multicolumn{2}{|c|}{$\begin{array}{l}\text { ENGAGE AF-TIMI } 48 \\
\text { Kato JAHA } 2016\end{array}$} \\
\hline Patients $\geq 75$ y n (\%) & \multicolumn{2}{|c|}{$\begin{array}{c}7258 / 18,113 \\
(40.1 \%)\end{array}$} & $\begin{array}{c}6229 / 14,264 \\
(43.7 \%)\end{array}$ & $\begin{array}{c}5678 / 18,201 \\
(31.2 \%)\end{array}$ & $\begin{array}{c}1898 / 5599 \\
(33.9 \%)\end{array}$ & \multicolumn{2}{|c|}{$\begin{array}{c}8474 / 21,105 \\
(40.2 \%)\end{array}$} \\
\hline $\begin{array}{l}\text { TTR in patients } \geq 75 \\
\text { y control arm }\end{array}$ & \multicolumn{2}{|c|}{$\begin{array}{l}\text { TTR according } \\
\text { to age group was } \\
\text { not available }\end{array}$} & $\begin{array}{l}\text { TTR higher } \\
\text { in patients } \geq 75 \mathrm{y} \text {; } \\
\text { mean } 56.9 \% \\
( \pm 21.6 \%)\end{array}$ & $\begin{array}{c}\text { TTR higher in } \\
\text {; } \quad \text { patients } \geq 75 \text { y } \\
\text { Median } 67.2 \% \\
\text { (IQR } 53.7 \%-77.4 \%)\end{array}$ & & \multicolumn{2}{|c|}{$\begin{array}{c}\text { TTR higher } \\
\text { in patients } \geq 75 \text { y } \\
\text { Median } 69.6 \% \\
\text { (IQR } 57.1 \%-78.3 \% \text { ) }\end{array}$} \\
\hline Dose & $\begin{array}{c}\text { Dabigatran } \\
150 \mathrm{mg}\end{array}$ & $\begin{array}{c}\text { Dabigatran } \\
110 \mathrm{mg}\end{array}$ & Rivaroxaban & Apixaban & Apixaban & $\begin{array}{l}\text { High-dose } \\
\text { Edoxaban }\end{array}$ & $\begin{array}{l}\text { Low-dose } \\
\text { Edoxaban }\end{array}$ \\
\hline Stroke/SE HR $(95 \% \mathrm{CI})$ & $0.67(0.49-0.90)$ & $0.88(0.66-1.17)$ & $0.80(0.63-1.02)$ & $0.71(0.53-0.95)$ & $0.33(0.19-0.54)$ & $0.83(0.67-1.04)$ & $1.12(0.91-1.40)$ \\
\hline Major bleeding $\mathrm{HR}(95 \% \mathrm{CI})$ & $1.18(0.98-1.42)$ & $1.01(0.83-1.23)$ & $1.11(0.92-1.34)$ & $0.64(0.52-0.79)$ & $1.21(0.69-2.12)$ & $0.83(0.70-0.99)$ & $0.47(0.38-0.58)$ \\
\hline IC bleeding HR $(95 \% \mathrm{CI})$ & $0.42(0.25-0.70)$ & $0.37(0.21-0.64)$ & $0.80(0.50-1.28)$ & $0.34(0.20-0.57)$ & $0.81(0.28-2.35)$ & $0.40(0.26-0.62)$ & $0.31(0.19-0.49)$ \\
\hline GI bleeding HR $(95 \% \mathrm{CI})$ & $1.79(1.35-2.37)$ & $1.39(1.03-1.98)$ & n.a. & - & n.a. & $1.32(1.01-1.72)$ & $0.72(0.53-0.98)$ \\
\hline
\end{tabular}

Y, years; n, number; TTR, time in therapeutic range; IQR, interquartile range; N.A., not applicable; SE, systemic embolism; HR, hazard ratio; CI, confidence index; IC, intracranial; GI, gastrointestinal; n.a., not available. From Bo et al, Eur J Intern Med 2017;41:18-27, with permission. ${ }^{10}$

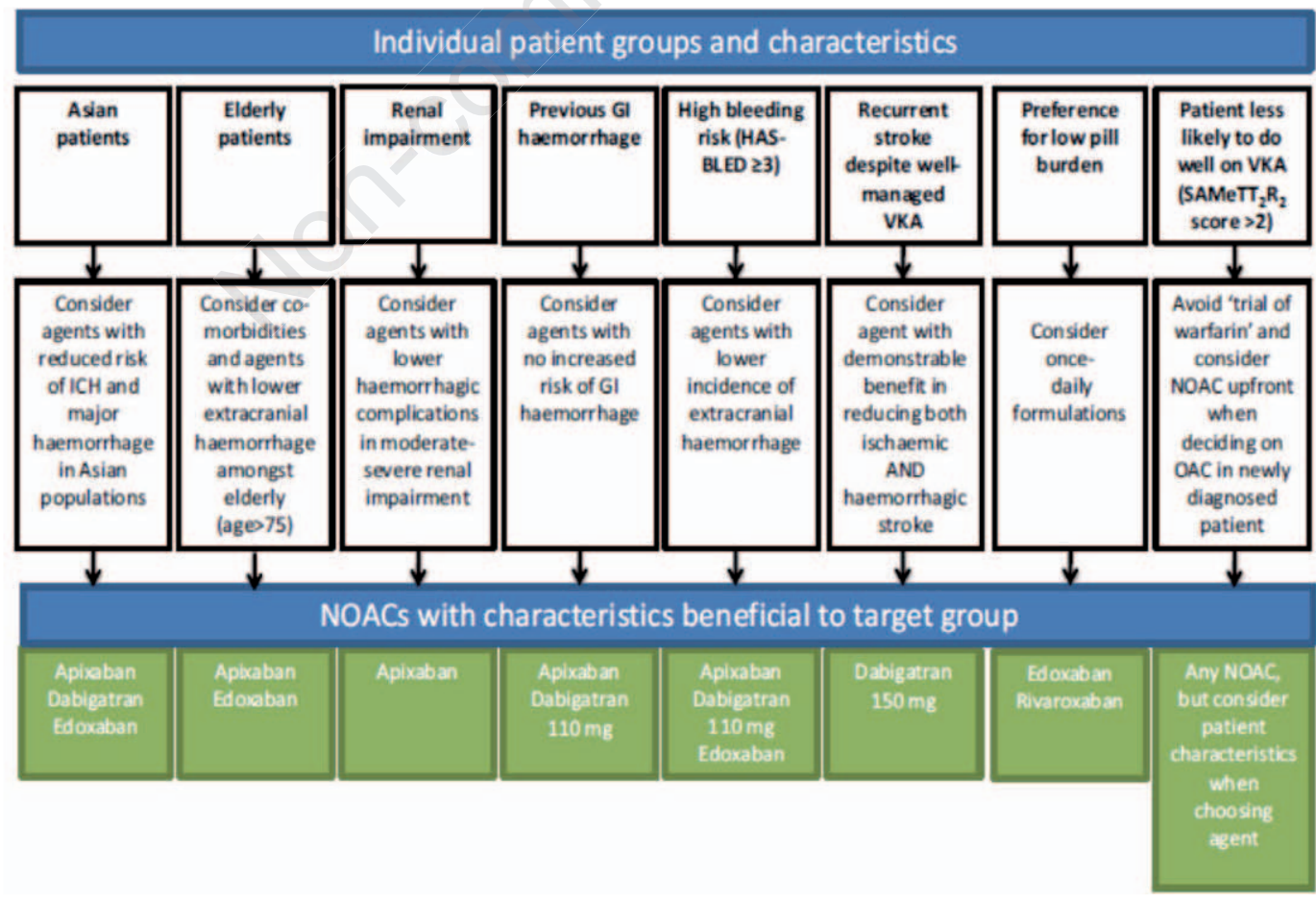

Figure 1. Therapeutic decisional flow-chart for AF patients candidate to OAT. From Shields and Lip, J Intern Med 2015;278:1-18, with permission. ${ }^{11}$ 


\section{References}

1. Sinnaeve PR, Brueckmann M, Clemens A, et al. Stroke prevention in elderly patients with atrial fibrillation: challenges for anticoagulation. J Intern Med 2012;271:15-24.

2. Chugh SS, Havmoeller R, Narayanan $\mathrm{K}$, et al. Worldwide epidemiology of atrial fibrillation: a Global Burden of Disease 2010 Study. Circulation 2014;129:837-47.

3. Kirchhof P, Benussi S, Kotecha D, et al. 2016 ESC Guidelines for the management of atrial fibrillation developed in collaboration with EACTS. Eur Heart J 2016;37:2893-962.

4. Pugh D, Pugh J, Mead GE. Attitudes of physicians regarding anticoagulation for atrial fibrillation: a systematic review. Age Ageing 2011;40:675-83.

5. Di Pasquale G, Mathieu G, Maggioni AP, et al. Current presentation and management of 7148 patients with atrial fibrillation in cardiology and internal medicine hospital centers: the ATA AF study. Int J Cardiol 2013;167:2895-903.

6. Bo M, Li Puma F, Badinella Martini M, et al. Health status, geriatric syndromes and prescription of oral anticoagulant therapy in elderly medical in-patients with atrial fibrillation: a prospective observational study. Int J Cardiol 2015; 187:123-5.

7. Bo M, Sciarrillo I, Maggiani G, et al. Health status, geriatric syndromes and prescription of oral anticoagulant therapy in elderly medical inpatients with atrial fibrillation. Geriatr Gerontol Int 2016 [Epub ahead of print].

8. Hess PL, Mirro MJ, Diener H-C, et al.
Addressing barriers to optimal oral anticoagulation use and persistence among patients with atrial fibrillation: Proceedings, Washington, DC, December 3-4, 2012. Am Heart J 2014; 168:239-47.e1.

9. Granziera S, Cohen AT, Nante G, et al. Thromboembolic prevention in frail elderly patients with atrial fibrillation: a practical algorithm. J Am Med Dir Assoc 2015;16:358-64.

10. Bo M, Grisoglio E, Brunetti E, et al. Oral anticoagulant therapy for older patients with atrial fibrillation: a review of current evidence. Eur J Intern Med 2017;41:18-27.

11. Shields AM, Lip GYH. Choosing the right drug to fit the patient whrn selecting oral anticoagulant for stroke prevention in atrial fibrillation. $\mathrm{J}$ Intern Med 2015;278:1-18. 